\title{
Effect of Body Condition Score at Lambing (BCSL) on Postpartum Performance of Nellore Brown Ewes
}

\author{
V. Anusha ${ }^{1}$, A. Anitha ${ }^{1 *}$, S. Jagadeeswara Rao ${ }^{1}$ and M. Muralidhar ${ }^{2}$ \\ ${ }^{1}$ Department of Livestock Production Management, Nandamuri Taraka Ramarao \\ College of Veterinary Science, Gannavaram-521 102, Andhra Pradesh, India \\ ${ }^{2}$ Department of Animal Genetics and Breeding, College of Veterinary Science, \\ Garividi-535101, Andhra Pradesh, India
}

*Corresponding author

\section{Keywords \\ Body Condition Score (BCS), BCS at lambing (BCSL), Gain in BCS (GBCS), Loss in BCS (LBCS), Postpartum changes}

Article Info

Accepted:

10 November 2020

Available Online:

10 December 2020

\section{A B S T R A C T}

To know the effect of Body Condition Score at lambing (BCSL) on postpartum changes a study was carried out at the sheep unit of Livestock Farm Complex, NTR College of Veterinary Science, Gannavaram and sheep flocks of farmers in and around Gannavaram of Krishna district of Andhra Pradesh. A total of 60 Nellore (Brown) ewes were selected to study the postpartum changes. The ewes were in the BCS range of $2.50-4.00$ at lambing. Majority of the ewes (49) were in the BCS of $2.50-3.74$ at lambing have reduced their body condition during early lactation and so the minimum BCS of $2.00-2.74$ was recorded for majority of the ewes (46). The mean BCSL was 3.15 which was decreased to 2.91 at first week postpartum, further decreased to 2.38 by 12 weeks postpartum and later on increased gradually to 2.64 by 18 weeks postpartum. LBCS of the test flock ranged from 0.50 to 1.25 with a mean value of 0.80 . GBCS of the test flock ranged from 0.25 to 0.50 with a mean value of 0.28 . Minimum BCS of the test flock ranged from 2.00 to 3.00 with a mean value of 2.34. The highest CV (18.94) of BCS in ewes was observed at 5 weeks postpartum and the least (12.04) at 14 and 16 weeks postpartum. The CV of LBCS was 24.27 and the CV of GBCS was 35.17 at 18 weeks postpartum. A significant $(\mathrm{P}<0.01)$ difference was observed between the ewes of different groups of BCSL in LBCS and minimum BCS. The mean BCS was decreased from first week to 12 weeks postpartum for the ewes of BCSL 2.50 to 2.99 and from first week to 13 weeks postpartum for the ewes of BCSL 3.00 to 3.49 and 3.50 to 4.00 , thereafter showed an increased trend for the ewes of three BCSL groups. The highest loss as well as gain in BCS was achieved by the BCSL group 3.50 to 4.00 compared to the BCSL group 2.50 to 2.99 and 3.00 to 3.49.The present study suggested an optimum BCS of $3.50-4.00$ at lambing so that the ewes could maintain the optimum body condition during lactation as well as replenish the body fat reserves by regaining BCS more efficiently. 


\section{Introduction}

The technique of Body Condition Score (BCS) is a means of subjectively assessing the degree of fatness or condition of the live animal and quick, easy and low cost management tool to increase ewe productivity and flock profitability. Body condition change is a good prediction technique of body reserves (Sanson et al., 1993) and is associated with seasonal variations in feed availability which are marked in tropical regions. There is an optimum condition score for each ewe in the flock at each stage of production cycle. Flock owners can make adjustments in the feeding programme by knowing condition score for the production stages to save money or prevent problems such as neonatal lamb mortality attributable to ewe condition. When determining the nutritional status of ewe for poorer condition animals, BCS was a better technique than fat scoring and an alternative for live weight (Van Burgel et al., 2011). BCS of ewes at mating had a significant effect on the reproductive performance of ewes (EsmaeiliZadeh et al., 2004) and its productivity (Vatankhah and Salehi, 2010). BCS of ewes at lambing has great influence on ewe condition after lambing. Achievement of high $\mathrm{BCS}$ at late pregnancy and at the time of lambing improve the lamb growth to weaning (Mathias-Davis et al., 2013). There was no data on the effect of BCS at lambing on the post partum performance of Nellore sheep breed. So, an attempt was made to study the effect of BCS at lambing (BCSL) on postpartum changes, loss in BCS (LBCS) and gain in BCS (GBCS) in Nellore Brown ewes.

\section{Materials and Methods}

The present study was carried out at the sheep unit of Livestock Farm Complex, NTR College of Veterinary Science, Gannavaram and four sheep flocks of farmers in and around Gannavaram of Krishna district of Andhra Pradesh. The Gannavaram town is situated at an elevation of 12 meters above sea level on $81^{\circ}$ longitude and $16.5^{\circ}$ latitude. Average temperature recorded was $33^{\circ} \mathrm{C}$ and average humidity was $70 \%$ during the period of this study. A BCS scale of 1 to 5 developed by Maurya et al., (2008) was used to score the ewes which are suitable in scoring of ewes under Indian conditions. This method considers the muscle over skeleton and hollow in the flanks below the loin for assessing the fat cover. A score of ' 1 ' considered as emaciated condition and a score of ' 5 ' considered as obese condition.

\section{Assigning of score}

Scoring is done by using the hand to feel for the fullness of muscling and fat cover over and around the vertebrae in the loin region. The skeletal check points observed by palpation were 1 . The spinous processes in the centre of the sheep's back behind the last rib and in front of its hip bone 2. the tips of the transverse processes 3 . the fullness of muscle and fat cover between spinous and transverse processes 4 . hollow in the flanks below the loin. After each check point was observed by palpation the scores were recorded and an average BCS was assigned to the ewe. Ewe showing the skeletal check points is presented in Figure 1. The ewes in the present study were maintained under semi-intensive production system in well ventilated sheds with asbestos roofing, open area for free movement and under proper hygienic conditions. Ewes were fed daily with concentrate feed at the rate of about 350 grams per head per day in addition to grazing. The animals had ad libitum access to good quality drinking water. Prophylactic measures against sheep diseases were carried out as prescribed by the health calendar of the institute to ensure that the animals were in healthy condition throughout the study. 


\section{Postpartum changes}

Sixty Nellore Brown ewes were selected to study the postpartum changes in a 3 X 20 CRD [3 groups divided based on BCS at lambing (BCSL)]. BCS of ewes were recorded at 2 weeks before lambing, on the day of lambing and at weekly intervals up to 18 weeks post lambing. Ewes were divided into 3 groups based on the BCS on the day of lambing as Group I - between 2.50 - 2.99, Group II - between 3.00 - 3.49 and Group III between $3.50-4.00$.

\section{BCSL and loss in BCS / Gain in BCS (LBCS/GBCS)}

The ewes were scored at weekly intervals from lambing to 18 weeks as LBCS/ GBCS to study the postpartum changes in BCS. BCSL was the first BCS assigned on the day of lambing.

LBCS was calculated as the difference between BCSL and minimum BCS, where minimum BCS refers to the lowest BCS obtained during the study period of 18 weeks. GBCS was calculated as the difference between minimum BCS and BCS obtained at the end of the study period of 18 weeks.

The data collected during the period of study were scrutinized and tabulated. The data were subjected to frequency, percentages, arithmetic mean, standard error and analysis of variance following the statistical methods according to Snedecor and Cochran (1994) as implemented in SPSS (Statistical Package for the Social Sciences) statistical package version 21 .

\section{Results and Discussion}

The frequency tabulation of BCSL and minimum BCS of test flock of 60 ewes showed in Table 1. Outof 60 ewes used for postpartum changes in BCS, more number of ewes were in the BCS range of $2.75-2.99$ and 3.25 - 3.49 at lambing followed by BCSL range of $2.50-2.74,3.00-3.24,3.50-3.74$, $4.00-4.24$ and $3.75-3.99$. There were no ewes in either poor (below 2.00) or obese (5.00) body condition at lambing. It showed that the ewes in gestation and near to parturition were maintained on good plane of nutrition resulted in ideal BCSL. The values of BCSL are similar to the findings of Maurya et al., (2008). Out of 60 ewes tested for the postpartum changes by recording minimum BCS values during early lactation of the test period of 18 weeks, more number of ewes had the minimum BCS of $2.00-2.24$ (21) followed by $2.50-2.74$ (13). Majority of the ewes (49) were in the BCS of $2.50-3.74$ at lambing have reduced their body condition during early lactation as the fat reserves were mobilized for milk production and so the minimum BCS of $2.00-2.74$ was recorded for majority of the ewes (46). The relative frequency values were shown as per the frequencies of the corresponding BCSL and minimum BCS, whereas the cumulative frequency values were increased due to the addition of relative frequencies showed similar trend as that of frequencies.

The BCSL and mean weekly postpartum changes of BCSL groups 2.50-2.99, $3.00-$ 3.49 and 3.50-4.00 is presented in Table 2. The BCSL and weekly postpartum changes of BCSL group 2.50 - 2.99 showed that there was a gain in mean BCS of 0.03 unit from 2 weeks before lambing to 1 week before lambing. The mean BCS value remained same from 1 week before lambing to BCSL. There was a loss in mean BCS of 0.25 unit from BCSL to the first week postpartum and loss in BCS was continued up to 12 weeks postpartum. The mean postpartum losses ranged from 0.24 to 0.64. The BCSL and weekly postpartum changes of BCSL group $3.00-3.49$ revealed that there was no loss in 
mean BCS of ewes from 2 weeks before lambing to BCSL. There was a loss in mean BCS of 0.23 unit from BCSL to first week postpartum and loss in BCS was continued up to 13 weeks postpartum. The mean postpartum losses ranged from $0.23-0.79$. The BCSL and weekly postpartum changes of BCSL group $3.50-4.00$ showed that there was no loss in mean BCS of ewes from 2 weeks before lambing to BCSL. There was a loss in mean BCS of 0.25 unit from BCSL to first week postpartum and loss in BCS was continued up to 13 weeks postpartum. The mean postpartum losses ranged from 0.25 0.94. However, these losses were found to be recouped during the remaining postpartum study period of 18 weeks as the ewes showed improvement in body condition. The loss in BCS during first 12 and 13 weeks after lambing is mainly because of mobilization of body fat reserves for milk production. The regain in the BCS after this was mainly due to replenishing of body fat reserves by the ewes after weaning of lambs. Based on the results at 18 weeks postpartum it can be predicted that ewes might have regained the normal BCS.

The results of Table 2 revealed that ewes with BCSL group $3.00-3.49$ and $3.50-4.00$ lost BCS of 0.79 and 0.94 , respectively whereas ewes with BCSL of $2.50-2.99$ lost BCS of only 0.64. This indicated that ewes with higher BCSL lost more BCS and it was also observed that they have reached minimum BCS one week later than the ewes with BCSL $2.50-2.99$. This was in agreement with the general consensus, that the ewes with excessive fat at lambing lose excessive body reserves as the fat reserves could be mobilized too rapidly.

The BCSL, LBCS, GBCS and minimum BCS of the BCSL groups $2.50-2.99,3.00-3.49$ and $3.50-4.00$ is presented in Table 3 . The mean BCSL of test flock was 3.15. The mean
LBCS was 0.80 and mean GBCS was 0.28. The results showed that the mean LBCS was higher by 0.56 units than mean GBCS over 18 weeks postpartum. However, the ewes might have regained LBCS in the subsequent weeks which were proved by GBCS of 0.26 within 6 weeks from 13 weeks postpartum. The mean value of minimum BCS over the period of 18 weeks postpartum was 2.34. The results showed that though there was loss in body fat reserves due to milk production the ewes could maintain a mean minimum BCS value of 2.34. This indicated that the ewes have not gone down to poor body condition of below 2.00. However, Maurya et al., (2008) suggested an optimum BCS of 3.00 during lactation.

The relationship between LBCS/GBCS of ewes and their BCSL is depicted in Figure 2. The line graph showed that LBCS has increased for ewes with BCSL of 3.00 to 3.49 and 3.50 to 4.00 whereas no much variation was shown by the line graph of GBCS for all the 3 BCSL groups. ANOVA of LBCS, GBCS and minimum BCS of BCSL groups $2.50-2.99,3.00-3.49$ and $3.50-4.00$ is presented in Table 4. The ewes of BCSL group 3.50- 4.00 had significantly $(\mathrm{P}<0.01)$ more LBCS followed by BCSL group $3.00-$ 3.49 and $2.50-2.99$. Ewes of BCSL group $3.50-4.00$ showed higher gain in BCS (0.30) followed by BCSL group 3.00 - 3.49 (0.28) and BCSL group $2.50-2.99(0.27)$. The results indicated that the magnitude of body condition loss and gain depended on BCSL.

These findings are in consensus with Borg et al., (2009) and Mathias - Davis et al., (2011) who reported that ewes which appear better able to utilise their body fat reserves during gestation and lactation, that is maintain condition in early gestation and then lose condition during lactation, perform better than other ewes 
Table.1 Frequency tabulation of BCSL and minimum BCS of test flock

\begin{tabular}{|c|c|c|c|c|c|c|}
\hline \multirow{2}{*}{ BCS } & \multicolumn{2}{|c|}{ Frequency } & \multicolumn{2}{c|}{ Relative frequency } & \multicolumn{2}{c|}{ Cumulative frequency } \\
\cline { 2 - 7 } & BCSL & $\begin{array}{c}\text { Minimum } \\
\text { BCS }\end{array}$ & BCSL & $\begin{array}{c}\text { Minimum } \\
\text { BCS }\end{array}$ & BCSL & $\begin{array}{c}\text { Minimum } \\
\text { BCS }\end{array}$ \\
\hline $\mathbf{1 . 0 0}-\mathbf{1 . 2 4}$ & 0 & 0 & 0 & 0 & 0 & 0 \\
\hline $\mathbf{1 . 2 5}-\mathbf{1 . 4 9}$ & 0 & 0 & 0 & 0 & 0 & 0 \\
\hline $\mathbf{1 . 5 0}-\mathbf{1 . 7 4}$ & 0 & 0 & 0 & 0 & 0 & 0 \\
\hline $\mathbf{1 . 7 5}-\mathbf{1 . 9 9}$ & 0 & 0 & 0 & 0 & 0 & 0 \\
\hline $\mathbf{2 . 0 0}-\mathbf{2 . 2 4}$ & 0 & 21 & 0 & 0.35 & 0 & 0.35 \\
\hline $\mathbf{2 . 2 5}-\mathbf{2 . 4 9}$ & 0 & 12 & 0 & 0.20 & 0 & 0.55 \\
\hline $\mathbf{2 . 5 0}-\mathbf{2 . 7 4}$ & 09 & 13 & 0.15 & 0.22 & 0.15 & 0.77 \\
\hline $\mathbf{2 . 7 5}-\mathbf{2 . 9 9}$ & 11 & 11 & 0.18 & 0.18 & 0.33 & 0.95 \\
\hline $\mathbf{3 . 0 0}-\mathbf{3 . 2 4}$ & 09 & 03 & 0.15 & 0.05 & 0.48 & 1 \\
\hline $\mathbf{3 . 2 5}-\mathbf{3 . 4 9}$ & 11 & 0 & 0.18 & 0 & 0.66 & 1 \\
\hline $\mathbf{3 . 5 0} \mathbf{- 3 . 7 4}$ & 09 & 0 & 0.15 & 0 & 0.81 & 1 \\
\hline $\mathbf{3 . 7 5}-\mathbf{3 . 9 9}$ & 04 & 0 & 0.07 & 0 & 0.88 & 1 \\
\hline $\mathbf{4 . 0 0}-\mathbf{4 . 2 4}$ & 07 & 0 & 0.12 & 0 & 1 & 1 \\
\hline $\mathbf{4 . 2 5}-\mathbf{4 . 4 9}$ & 0 & 0 & 0 & 0 & 1 & 1 \\
\hline $\mathbf{4 . 5 0}-\mathbf{4 . 7 4}$ & 0 & 0 & 0 & 0 & 1 & 1 \\
\hline $\mathbf{4 . 7 5}-\mathbf{5 . 0 0}$ & 0 & 0 & 0 & 0 & 1 & 1 \\
\hline
\end{tabular}

Table.2 BCSL and mean weekly postpartum changes of BCSL groups $2.50-2.99,3.00-3.49,3.50-4.00$

\begin{tabular}{|c|c|c|c|}
\hline \multirow{2}{*}{ Weeks } & \multicolumn{3}{|c|}{ BCSL group } \\
\cline { 2 - 4 } & BCSL group 2.50- & BCSL group $3.00-$ & BCSL group $3.50-$ \\
\hline & 2.99 & 3.49 & 3.00 \\
\hline 2 weeks before lambing & 2.61 & 3.14 & 3.69 \\
\hline 1 week before lambing & 2.64 & 3.14 & 3.69 \\
\hline BCSL & 2.64 & 3.14 & 3.69 \\
\hline 1 week & 2.39 & 2.91 & 3.44 \\
\hline 2 weeks & 2.39 & 2.89 & 3.44 \\
\hline 3 weeks & 2.39 & 2.88 & 3.36 \\
\hline 4 weeks & 2.39 & 2.79 & 3.26 \\
\hline $\mathbf{5}$ weeks & 2.31 & 2.69 & 3.20 \\
\hline 6 weeks & 2.26 & 2.66 & 3.20 \\
\hline 7 weeks & 2.15 & 2.65 & 3.14 \\
\hline $\mathbf{8}$ weeks & 2.15 & 2.61 & 2.98 \\
\hline 9 weeks & 2.05 & 2.60 & 2.98 \\
\hline $\mathbf{1 0}$ weeks & 2.00 & 2.49 & 2.96 \\
\hline $\mathbf{1 1}$ weeks & 2.00 & 2.38 & 2.81 \\
\hline $\mathbf{1 2}$ weeks & 2.00 & 2.36 & 2.76 \\
\hline $\mathbf{1 4}$ weeks & 2.15 & 2.35 & 2.75 \\
\hline $\mathbf{1 5}$ weeks & 2.19 & 2.36 & 2.76 \\
\hline $\mathbf{1 6}$ weeks & 2.23 & 2.46 & 2.83 \\
\hline $\mathbf{1 7}$ weeks & 2.25 & 2.60 & 2.89 \\
\hline $\mathbf{1 8}$ weeks & 2.25 & 2.61 & 2.95 \\
\hline & 2.28 & 2.64 & 3.00 \\
\hline
\end{tabular}


Table.3 LBCS, GBCS and minimum BCS of ewes of different groups of BCSL in the test flock

\begin{tabular}{|c|c|c|c|c|c|c|c|c|}
\hline \multirow{2}{*}{ Groups } & \multicolumn{2}{|c|}{ BCSL } & \multicolumn{2}{c|}{ LBCS } & \multicolumn{2}{c|}{ GBCS } & \multicolumn{2}{c|}{ Minimum BCS } \\
\cline { 2 - 10 } & Mean & SE & Mean & SE & Mean & SE & Mean & SE \\
\hline $\mathbf{2 . 5 0}-\mathbf{2 . 9 9}$ & 2.64 & 0.02 & 0.64 & 0.02 & 0.27 & 0.01 & 2.00 & 0.00 \\
\hline $\mathbf{3 . 0 0}-\mathbf{3 . 4 9}$ & 3.14 & 0.02 & 0.79 & 0.02 & 0.28 & 0.02 & 2.35 & 0.03 \\
\hline $\mathbf{3 . 5 0}-\mathbf{4 . 0 0}$ & 3.69 & 0.04 & 0.94 & 0.03 & 0.30 & 0.29 & 2.68 & 0.04 \\
\hline Overall & 3.15 & 0.05 & 0.80 & 0.02 & 0.28 & 0.01 & 2.34 & 0.04 \\
\hline
\end{tabular}

Table.4 ANOVA for BCSL, LBCS, GBCS, and minimum BCS of different groups of BCSL in the test

\begin{tabular}{|c|c|c|c|c|c|}
\hline \multirow{2}{*}{ BCSL } & Source & Df & SS & MSS & F- ratio \\
\hline \multirow{2}{*}{ LBCS } & Between groups & 2 & 11.03 & 5.51 & $232.388^{* *}$ \\
\cline { 2 - 6 } & within groups & 57 & 1.35 & 0.02 & $36.124 * *$ \\
\cline { 2 - 6 } & Between groups & 2 & 1.24 & 0.622 & 0.017 \\
\hline \multirow{2}{*}{ GBCS } & within groups & 57 & 0.98 & 0.003 & 0.298 \\
\cline { 2 - 6 } & Between groups & 2 & 0.006 & 0.010 & $104.893 * *$ \\
\hline \multirow{2}{*}{ Minimum BCS } & within groups & 57 & 0.59 & 2.36 & 1.28 \\
\hline
\end{tabular}

** Significant $(\mathrm{P}<0.01)$

Table.5 CV of weekly postpartum changes, LBCS and GBCS of test flock

\begin{tabular}{|c|c|}
\hline Change in BCS & CV \\
\hline 2 weeks before lambing & 14.53 \\
\hline 1 week before lambing & 14.87 \\
\hline BCSL & 14.53 \\
\hline 1 week & 15.87 \\
\hline 2 weeks & 15.94 \\
\hline 3 weeks & 15.15 \\
\hline 4 weeks & 14.41 \\
\hline 5 weeks & 18.94 \\
\hline 6 weeks & 15.22 \\
\hline 7 weeks & 16.62 \\
\hline 8 weeks & 14.55 \\
\hline 9 weeks & 16.21 \\
\hline 10 weeks & 16.32 \\
\hline 11 weeks & 15.52 \\
\hline 12 weeks & 14.70 \\
\hline 13 weeks & 12.59 \\
\hline 14 weeks & 12.04 \\
\hline 15 weeks & 12.53 \\
\hline 16 weeks & 12.04 \\
\hline 17 weeks & 12.66 \\
\hline 18 weeks & 12.76 \\
\hline LBCS & 24.27 \\
\hline & 35.17 \\
\hline
\end{tabular}


Figure.1 Ewe showing the skeletal check points for BCS

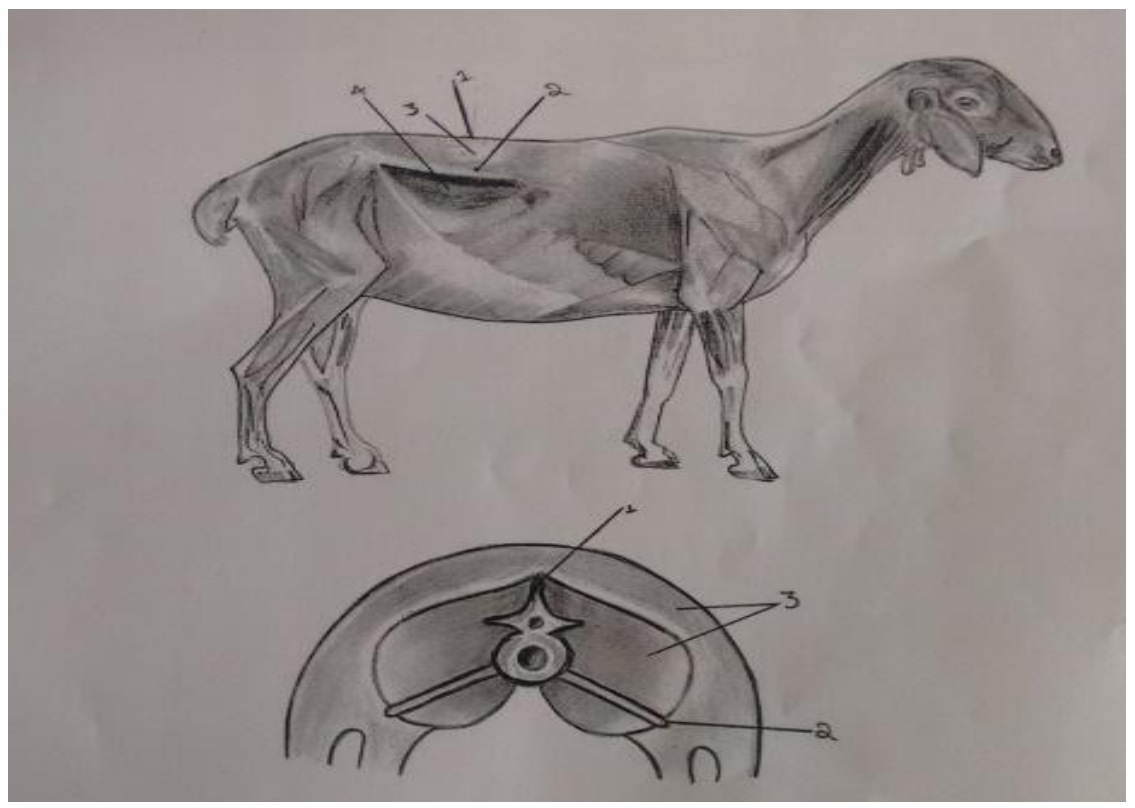

Figure.2 Relationship between LBCS/GBCS of ewes and their BCSL

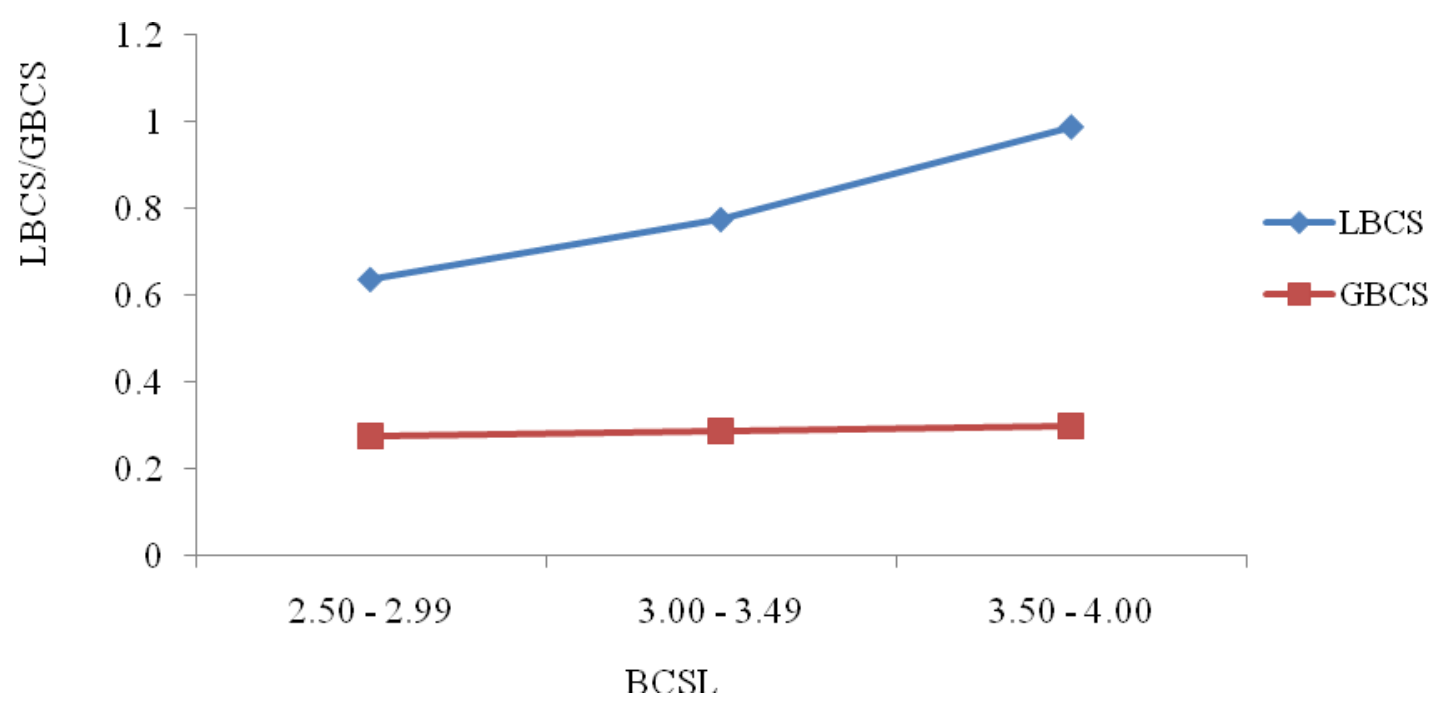

. Ewes with BCSL of $2.50-2.99$ and $3.00-$ 3.49 have gone down to a mean minimum BCS of 2.00 and 2.35, respectively during lactation whereas ewes with BCSL of $3.50-$ 4.00 could maintain a significantly $(\mathrm{P}<0.01)$ higher minimum BCS of 2.68 and also showed more gain in BCS subsequently. The results revealed that ewes with BCSL of $2.50-2.99$ have gone down to a minimum
BCS of 2.00 indicating thin body condition which may result in negative energy balance leading to metabolic disorders and also reduced performance in future.

The CV of weekly postpartum changes, LBCS and GBCS of the test flock presented in Table 5. The highest CV (18.94) of BCS in ewes was observed at 5 weeks postpartum 
and the least (12.04) at 14 and 16 weeks postpartum. The CV of LBCS was 24.27 and the CV of GBCS was 35.17 at 18 weeks postpartum. The ewes had comparatively more variation up to 12 weeks period of time than the GBCS from 13 to 18 weeks. The CV of LBCS and GBCS were comparable.

In conclusion, the present study suggested an optimum BCS of $3.50-4.00$ at lambing so that the ewes could maintain the optimum body condition during lactation as well as replenish the body fat reserves by regaining BCS more efficiently.

\section{References}

Borg, R C, Notter, D R and Kott, R W. 2009. Phenotypic and genetic associations between lamb growth traits and adult ewe body weights in western range sheep. Journal of Animal Science, 87: 3506-3514

Esmaeili-Zadeh A, Gharaei A and MiraeiAshtiani S R 2004. Effects of ewe live weight and body condition at mating on fertility and lambing season of Kurdy sheep in extensive production system. Pajouhesh and Sazandegi, 61: 8-16.

Mathias-Davis, H C, Shackell, G H, Greer, G J and Everett- Hincks, J M. 2011. The association of ewe body condition with weight of lamb weaned. Proceedings of the New Zealand Society of Animal Production, 71: 6265.

Mathias-Davis, H.C., Shackell, G.H., Greer, G.J., Bryant, A.I. and Everett-Hincks,

\section{How to cite this article:}

Anusha, V., A. Anitha, S. Jagadeeswara Rao and Muralidhar, M. 2020. Effect of Body Condition Score at Lambing (BCSL) on Postpartum Performance of Nellore Brown Ewes. Int.J.Curr.Microbiol.App.Sci. 9(12): 1000-1007. doi: https://doi.org/10.20546/ijcmas.2020.912.121
J.M. 2013. Ewe body condition score and the effect on lamb growth rate. Proceedings of the New Zealand Society of Animal Production 73: $131-135$.

Maurya, V P, Sejian, V, Kumar, D, Joshi, A, Naqvi, S M K and Karim, S A 2008. Body Condition Scoring system: A simple tool for optimizing productivity in sheep farms. Technical Bulletin, Central Sheep and Wool Research Institute, Avikanagar, Rajasthan

Sanson, D W, West, T R, Tatman, W R, Riley, M L, Judkins, M B and Moss, G E. 1993. Relationship of bodycomposition of mature ewes with condition score and body weight. Journal of Agricultural Science, 71: 1112-1116.

Snedecor G W and Cochran W G 1994.Statistical Methods. Oxford and IBH, Publishing company, New Delhi.

SPSS: Statistical Package for the Social Sciences version 21 .

Van Burgel A J, Oldham C M, Behrendt R, Curnow M, Gordon D J and Thompson A N 2011. The merit of condition score and fat scores as alternatives to live weight for managing the nutrition of ewes. Animal Production Science, 51: 834841.

Vatankhah, M. and Salehi, S A. 2010. Genetic and non-genetic factors affecting Lori-Bakhtiari ewe body weight and its relationship with productivity. Small Ruminant Research, 94: 98-102. 